\title{
On the use of Conversation Analysis and retrospection in intervention for children with language impairment
}

Christina Samuelsson and Charlotta Plejert

\author{
Linköping University Post Print
}

\section{Tweet}

N.B.: When citing this work, cite the original article.

Original Publication:

Christina Samuelsson and Charlotta Plejert, On the use of Conversation Analysis and retrospection in intervention for children with language impairment, 2015, Child Language Teaching and Therapy, (31), 1, 19-36.

http://dx.doi.org/10.1177/0265659014532477

Copyright: SAGE Publications (UK and US)

http://www.uk.sagepub.com/home.nav

Postprint available at: Linköping University Electronic Press

http://urn.kb.se/resolve?urn=urn:nbn:se:liu:diva-114980 


\section{Introduction}

Models of speech and language intervention for communicative disabilities vary from very structured programmes to more interactive and ecological methods (Fey, 1986). Ideally, a model for intervention should fit the interests and personality of the patient, focus on crucial aspects of speech and language, and be suited to the patient's everyday communication needs (Johnston, 2006). In clinical practice, it may be difficult to make the goals of intervention have an impact on everyday interaction. Given the importance of the relationship between everyday interaction and language intervention, relatively little research investigates clients' problems related to everyday interaction, and skills practiced in speech and language intervention.

For children with speech and language impairment (LI) and no other disabilities, the goals of speech and language intervention are often based on formal tests of the child's linguistic ability, and focus on the areas that the child has particular difficulties with as revealed by the tests. However, formal tests of linguistic skills may not necessarily reflect and capture skills that are relevant for the management of interaction with others in everyday life. The lack of ecological validity of management practice, if based solely on formal assessment, may also be related to problems with carryover of features from intervention to everyday interaction. For children with severe LI, both the ability and the opportunities for participation in social interaction may be hampered (Bishop, 1997). Cahill (2010) pointed out that children in general may require special management in clinical contexts in order to engage in their treatment, and this is particularly true for children with LI.

The present article addresses how features of everyday interaction and speech and language intervention may be captured and used for children with LI, their caretakers/relatives, and 
speech and language therapists (SLTs), within, as well as outside of clinical practice. Specifically, the study aims to explore the use of retrospection (Erickson and Schultz, 1982), based on Conversation Analysis (CA) methodology (e.g. Schegloff, 2007), and to establish if and how CA-based retrospection may contribute to raising participants' awareness of their own and others' interactional behaviours in ways that are relevant for intervention and everyday talk involving children with LI.

Retrospection entails the practice of watching and commenting on a previously videorecorded event, and has also been termed video-stimulated comments (Pomerantz, 2005), or video-assisted recall (Sillars et al., 2000). Thus, retrospection here refers to sessions where participants watch and comment on sequences of previously made video-recordings from intervention, as well as from situations captured in a variety of everyday settings.

\section{Conversation analysis of interaction involving children with $L I$}

The overall aim of CA is to investigate how social action is organized in interaction (Hutchby and Wooffitt, 2008; Schegloff, 2007). An important part of contemporary CA is videoanalysis, where the analyst focuses on what the participants in the films are doing, and what actions they orient to as relevant at a specific point in the interaction. Video- and audio-data are transcribed in very great detail according to specific conventions (e.g. Ochs et al., 1996; Mondada, 2006).

Traditionally, CA has to a great extent dealt with everyday talk produced by adults with no communication impairments. There are, however, an increasing number of CA-studies that address atypical interaction (e.g. Gardner and Forrester 2010; Norén et al., 2013; Wilkinson 2013 etc.). A recent volume on interactions in childhood, edited by Gardner and Forrester 
(2010) contains several contributions dealing with children in therapy-sessions (Hutchby, 2010; Tykkyläinen, 2010), educational settings (Radford and Mahon, 2010; Stribling and Rae, 2010), and medical consultation (Cahill, 2010). Various collaborative efforts that occur in interaction between adults and children are presented, demonstrating how children may be encouraged to actively engage or not in a specific task or setting. Cahill (2010), for example, describes how a doctor, by means of arranging the seating for patients (children and their caretakers) in a triangular fashion rather than knee-to-knee, enhances triadic talk. It is also demonstrated how doctors, by selecting the child as speaking partner at specific points during consultation, manages to engage the child in the talk.

There are a few studies in which CA has been used to describe and discuss intervention with children with LI (Merrils, 2009; Gardner, 2006; Tykkyläinen, 2010). Tykkyläinen (2010) investigated child-initiated repair sequences that occurred in interaction between seven children with LI (aged 4;11-6;0) and their SLTs in therapy tasks. The repair initiated by children with LI in interaction with SLTs was compared to repair sequences occurring in interaction between eight typically developing children (aged $4 ; 10-5 ; 1)$ and their mothers in a playful task at home. The analysis revealed that it was rare for children to initiate repair, and in both groups, children initiated repair to gain success in the task-activity at hand. Interestingly however, repair initiations by children with LI were primarily caused by problems in hearing, attention, or understanding, while repair initiations by typically developing children focused more on task-solving processes (Tykkyläinen, 2010). Tykkyläinen's study suggests that the analysis of repair provides important information on the interactional abilities of children with LI, relevant for therapy. It is useful to highlight specific interactional phenomena for interaction partners to become more sensitive to, for example, 
repair initiated by the child (p. 245). One way of raising participants' awareness is by means of retrospections as described in the present paper.

In another CA-based study, children with pragmatic language impairment (PLI), children with specific language impairment with no pragmatic difficulties (SLI), and a mainstream group were compared regarding their abilities to initiate repair (Merrison and Merrison, 2005). Children with PLI initiated repair less frequently than the other two groups. However, after a period of therapy focusing on pragmatic skills, the children with PLI showed marked improvement in initiating repair, which, in turn, may have a positive effect on their interactional skills.

\section{Intervention programmes that target interaction using retrospection}

There are several intervention programmes that focus on changing parents' responses to their children's contributions in interaction, such as provided within enhanced milieu teaching (Hancock and Kaiser, 2006) and conversational recast intervention (Camarata and Nelson, 2006). Enhanced milieu teaching is based on naturalistic strategies, and may be used to train communication skills, but is often also used to train specific linguistic structures, or more general linguistic features, such as mean length of utterance (Hancock and Kaiser, 2006). The purpose of conversation recast intervention is to parallel natural language acquisition by responding to children's contributions with recasts that model both the forms that the child is currently using, and forms that go beyond the child's current level of performance (Camarata and Nelson, 2006). However, these programmes do not focus on interactional behaviour in either children or adults. Rather, they deal with specific grammatical or phonological structures through interactional behaviour. Neither do they use video recordings or retrospection as a regularized feature of the programme. 
There are CA-based intervention programmes that target interaction and use retrospective sessions for adults with aphasia (Lock et al., 2001). The programme Supporting Partners of People with Aphasia in Relationships and Conversation, SPPARC, (Lock et al., 2001) involves participants' video-recordings of their own interaction in their home-environment. These recordings are assessed by an SLT, who identifies certain areas of interaction that he/she considers important to work with in collaboration with the participants. In this way, participants are made aware of their particular interactional patterns, and also trained in changing patterns that are unhelpful for them in their everyday interaction with each other.

There are few intervention programmes used with children that include retrospection. However Talking about Speech is designed for SLTs to use with school support assistants, students, and parents to enhance their implementation of therapy for children with speech sound problems (Gardner, 2006). The programme covers different elicitation strategies, how to deal with "a good try", and how to deal with errors. CA and retrospection are used to focus on the adult participant's interactional behaviour, for example, by shaping the adult's immediate responses to the child's contributions within the sequence of therapy talk. The programme lasts for six weeks, and weekly meetings consider how the targeted features can be carried over to everyday tasks. The programme has been evaluated within a pilot study (Gardner, 2006) that demonstrated direct changes in adult therapy talk. After the programme, the adult participants also felt more positive about their role in therapy, and had a greater understanding about the therapeutic process than before the programme. It should be noted that this programme primarily deals with the adults' implementation of features targeted in phonological intervention, whereas the present study aims to highlight goals of intervention as 
well as interactional behaviours of children other than those specifically in focus in intervention.

Although CA-based intervention involving children with LI are sparse, two related programmes are based on the analysis of interactional patterns and practices, the Marte Meo method (Aarts, 2000; Ovreeide and Hafstad, 1996), and The Hanen Programme (Pepper and Weitzman, 2004). These programmes have shown positive changes in children's behaviours, based on changes in adult communicative actions.

The Marte Meo method (MM) is based on the notion that children develop and grow in interaction with supportive adults, and assumes that there is a prototype for developmentally supportive dialogue that provides the child with relevant support and information (Aarts, 2000; Ovreeide and Hafstad, 1996). The method was originally designed for children with behavioural problems and analysis and intervention are the two basic elements (Aarts, 2000). The focus of the programme is to help the parent or the teacher to detect the communicative needs of the child, and to stimulate a modification of the adults' communicative behaviour. In the final step of the programme, the adult is instructed to practise new types of behaviour in everyday situations. In an evaluation study, children who had received treatment with MM decreased their externalizing behaviour significantly (Axberg et al., 2006). The programme has not yet been used with children with LI.

It Takes Two To Talk - the Hanen Program (Pepper and Weitzman, 2004), is designed for groups of parents of children with speech and language problems. Throughout the programme, parents and children are video recorded, and the recordings used to coach parents in how to adapt their communication practices to their child's level of development, based on 
a model for developmentally supportive features of dialogue. Evaluation studies have revealed that the programme did not bring about change in children's receptive and expressive language skills. However, positive changes were observed in children's social interaction skills (Coulter and Gallagher, 2001; Pennington et al., 2009).

These programmes make use of video-analysis for the purpose of intervention, and demonstrate the usefulness of retrospection in order to raise participants' awareness of their interactional behaviours, generating information useful to caregivers as well as therapists. The present study makes use of retrospection and employs a CA methodology because it is "emic" (Garfinkel and Sacks, 1986) in nature, i.e. it aims to identify what the participants of a recorded interactional event themselves orient to in a particular setting, and at a particular point in the interaction.

\section{Conversation Analysis in combination with talk-extrinsic data}

CA is not commonly combined with methods such as retrospection, and use of this kind of "talk-extrinsic data", e.g. comments on interactional behaviour generated after an original recording, together with CA, has been thoroughly discussed and debated (cf. Antaki, 2012; Ford, 2012; Pomerantz, 2012 in a response to Waring et al., 2012). The main point of concern is the relationship between what practices can be demonstrably observed, and participants' retrospective, video-stimulated comments. Waring et al. (2012) suggested that talk-extrinsic data may confirm CA observations, specify assumptions of why something takes place in interaction, disambiguate an earlier analysis, and correct an initial analysis. In response to this claim, Antaki (2012), Ford (2012) and Pomerantz (2012) stress that it is important not to make straightforward assumptions of peoples' underlying intentions for their interactional 
practises only based on their self-reports (Ford, 2012), as these are in themselves (re)constructions of a past event.

\section{Aims of the study}

For children with LI, there is currently little systematic use of programmes that target interaction in language intervention, and very few programmes that utilize retrospection as part of intervention (see above for some exceptions). There have not been any studies in which CA-based retrospection, where recordings from the children's everyday environments and traditional intervention have been analysed and discussed, with children with LI and their parents.

This study aims to explore the use of retrospection based on CA-methodology as a potentially fruitful method to be employed in language intervention for children with LI. Specifically, the study investigates if CA-based retrospection contributes to raising participants' awareness of their own and others' interactional behaviours in ways that are relevant for intervention and everyday talk involving children with LI. Results from the study may provide directions for the future development of how to optimize the use of retrospection in intervention for children with LI.

\section{Method}

\section{Participants}

Four children, Saga, Hanna, Ester and Emil, with mild to moderate LI participated in the study, (in Swedish clinical practice this diagnosis also comprises phonological impairment). None of the children was able to read. They were recruited from speech and language clinics 
in the South East of Sweden. Other participants were three SLTs working with the children, and parents (see table 1).

Table 1. Overview of participating children.

\begin{tabular}{|l|l|l|l|}
\hline Name & Sex & Age & Diagnosis \\
\hline Ester & F & $4: 11$ & $\begin{array}{l}\text { Phonological and } \\
\text { grammatical LI }\end{array}$ \\
\hline Saga & F & $5: 0$ & Expressive LI \\
\hline Hanna & F & $4: 10$ & Phonological LI \\
\hline Emil & M & $5: 2$ & Phonological LI \\
\hline
\end{tabular}

\section{Data}

Two sets of recorded data were used. The first data-set, used as a basis for retrospection, consisted of video recordings (535 minutes) from three settings involving each of the children with LI: Speech and language therapy sessions; interactions with family and friends at home; and interactions at the children's pre-schools. The second data-set consisted of audiorecordings of the interaction that took place between the researchers and the SLTs, children with LI, and their caretakers, during the retrospection session (see table 2). Interviews were also carried out with participants (see table 2).

Table 2. Overview of the data.

\begin{tabular}{|l|l|l|l|}
\hline Participant & Setting & Time & Type of data \\
\hline Ester & At home & 34.22 & Video \\
\hline & At the pre -school & 1.18 .41 & Video \\
\hline & Intervention & 30.35 & Video \\
\hline & Retrospection & 1.17 .31 & Audio \\
\hline
\end{tabular}




\begin{tabular}{|l|l|l|l|}
\hline Saga & At home & 2.15 .00 & Video \\
\hline & At the pre-school & 1.05 .04 & Video \\
\hline & Intervention & 25.06 & Video \\
\hline Hanna & Retrospection & 1.32 .51 & Audio \\
\hline & At home & 10.07 & Video \\
\hline & At the pre-school & 1.10 .36 & Video \\
\hline & Intervention & 18.36 & Video \\
\hline Emil & $\begin{array}{l}\text { Retrospection, SLT, } \\
\text { mother }\end{array}$ & 46.12 & Audio \\
\hline & At home & 1.19 .03 & Video \\
\hline & Intervention & 39.35 & Video \\
\hline & Retrospection mother & 1.22 .37 & Audio \\
\hline
\end{tabular}

\section{Procedure}

The procedure comprised five parts: 1) interviews, 2) video-recordings of language intervention and everyday interaction, 3) transcription and initial analysis of original videorecordings, 4) audio-recorded retrospections with the participating children, their caretakers, and SLTs, and 5) transcription and analysis of the audio-recorded interaction in the retrospections. The different analytical steps at play thus start with the transcription and initial analysis of the original recordings collected from language intervention and everyday settings of the children with LI, and ends with transcription and analysis of the audio-recorded interaction in the retrospections.

a) Analyses and transcriptions of the first data-set; recordings from language intervention and everyday settings 
The emic stance taken within CA, influenced how the recordings of interaction from intervention and everyday talk involving the children with LI (the first data-set), were initially analysed, and how specific sequences of talk were selected for viewing in subsequent retrospection sessions. The first step entailed watching these recordings numerous times, identifying phenomena of relevance in terms of goals of intervention, and everyday communication needs for the children with LI, their caretakers, and for SLTs. This resulted in the selection of a number of key-episodes to be used for the retrospection sessions, these were evenly distributed between everyday- and intervention data from each child with LI. Approximately five key-episodes of two to three minutes were used in each retrospection session. These were transcribed in accordance with CA-transcription conventions (Ochs et al., 1996), which enable transcriptions rich in detail. However, the level of detail had to be compromised somewhat in order to carry out retrospections in close proximity to the actual time of the initial recordings, and was also adapted so that the transcripts would be readerfriendly for participants (unfamiliar with reading transcriptions) during the retrospection session. Thus, for each key-episode to be used during the retrospection, a reader-friendly, but still fairly detailed, transcription excerpt was provided.

\section{b) Retrospections}

Retrospections were performed individually for each participant; first with the child and his/her parent/s (in one case, a grandmother also attended), then including the SLT, and finally with the SLT alone. In total, this procedure took approximately one hour for each child. The sessions were carried out either at the SLT department or in the homes of participants. The number of participants present at each session varied depending on how many relatives took part in the study. Either one or two researchers, and on some occasions, one or two research assistants, who were speech and language therapy students, were present. 
The retrospection sessions were semi-structured. Participants were asked to indicate during watching the recording any points of interest to them. The researchers also had some preplanned points for discussion, relating to the procedure of selecting key-episodes, where certain aspects of interaction had featured as relevant. If needed, these points of discussion were introduced by specific comments on interactional behaviour, or by direct questions regarding interaction. All participants had access to the transcriptions of key-episodes, which enhanced the common recognition of phenomena that were pointed out. Participants were not informed about any specific interactional features of the talk beforehand, but were asked to express their spontaneous thoughts and reactions as they watched the film. All talk during the retrospection session was audio recorded, and served as the second data-set of the study.

c) Analyses and transcriptions of the second data-set; audio recorded interaction from retrospections

When retrospections with all participants had been carried out, a similar analytical process as described for the first data-set (i.e. the recordings of the children's everyday environments, and intervention sessions) above, was conducted. Audio-recordings were repeatedly listened to as the initial step of the analysis, and subsequently transcribed according to CAconventions.

During analysis of the retrospection-data, a variety of comments relevant for the relationship between goals of intervention, and participants' everyday interaction needs, emerged. These comments were grouped into four categories: 1) Observations of well-functioning interaction strategies; 2) Observations of less well-functioning interaction strategies; 3) Assessment of positive performance; and 4) Comments relating to intervention. 


\section{Results}

For each extract included here a translation from Swedish into English is provided in italics in the transcript. Transcription conventions follow Ochs et al. (1996) with minor adaptations. A key to symbols used in transcription is given in Appendix One. The translation into English attempts to preserve the spoken language, social quality of the talk. At times, this means that it is not an exact verbatim translation. As Swedish and English are reasonably similar in terms of grammar, however, only a few modifications have had to be made. Back-channels (e.g."mm"), have not been translated.

\section{Observations of well-functioning interaction strategies}

This category comprises a variety of interactional practices that were observed and commented upon during the retrospection, both by the researchers, and by other participants present. What is referred to here, is an interactional behaviour of some participant (the child with LI, or someone else), that is beneficial for the child, in relation to the goals of intervention, or in terms of enhancing everyday interaction.

Excerpt 1 was generated in a retrospection session at the SLT clinic, involving Saga. It illustrates a moment in which the researcher has stopped the film in order to point to a strategy on the part of Saga's mother in interaction with her daughter. The film depicts an episode of talk between Saga, her older sister, and their mother at home as the girls are painting.

\section{Excerpt 1 .}

M: Mother, R1:Researcher 1, R2: Researcher 2

01 R1: men de ja tänkte på innan också att du väntar ut Saga väldigt

02 bra (.) för ibland börjar hon på en mening o så får hon inte

03 riktigt till de 


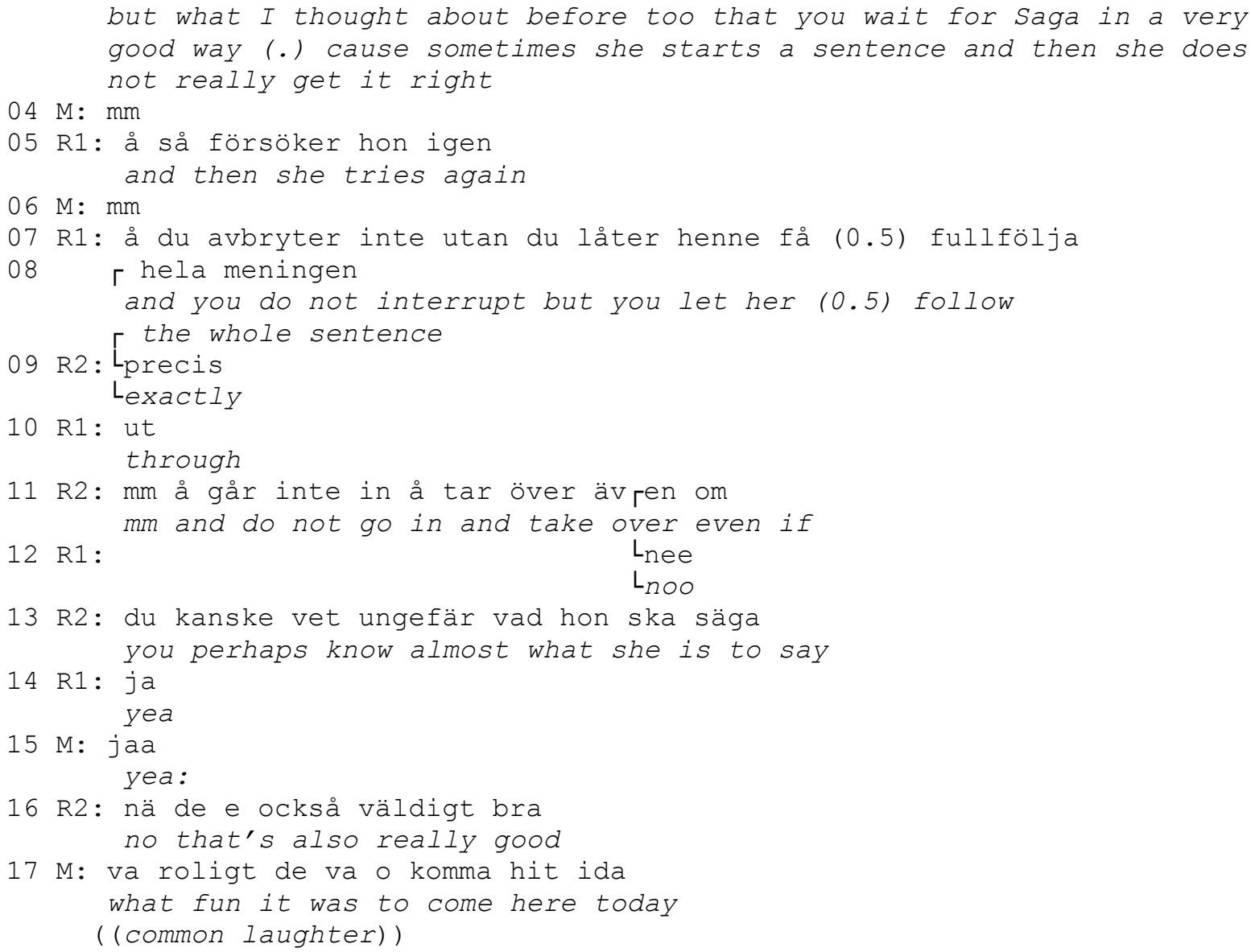

The comment by R1 (lines 01-03, 05, and 07-08) deals with an observation made in the film of how the mother waits for Saga to finish a turn that she has started, rather than interrupting her. This utterance is supported by minimal responses from the mother (lines 04, and 06). R2 also supports this (lines 09, 11, and 13), adding that this is something positive (line 16). Saga's mother then states that she enjoyed coming to the SLT today (line 17). The strategy pointed out as well-functioning by both researchers, concerns the mother giving space and time for Saga to develop and finish her utterance, which probably is beneficial for Saga's language development. This behaviour is also promoting self-corrections by Saga, which is preferred compared to corrections made by other participants (Schegloff et al.,1977). This excerpt illustrates how retrospection may be used to reinforce well-functioning strategies used by the parent. In this particular excerpt, the initiative on what to attend to comes from one of 
the researchers, but it was equally common with initiatives from other participants (with the exception from the children with LI - this issue will be returned to below).

\section{Observations of less well-functioning interaction strategies}

Excerpt 2 represents an example of the acknowledgment of a strategy that may be perceived as less beneficial in relation to the LI of Ester. The comment was generated in a retrospection session at the SLT clinic together with the parents and grandmother of Ester. In this episode, Ester's grandmother acknowledges an interactional feature occurring in the film that she finds interesting. The film depicts a play situation at the pre-school between Ester, her friend, and a pre-school teacher.

\section{Excerpt 2.}

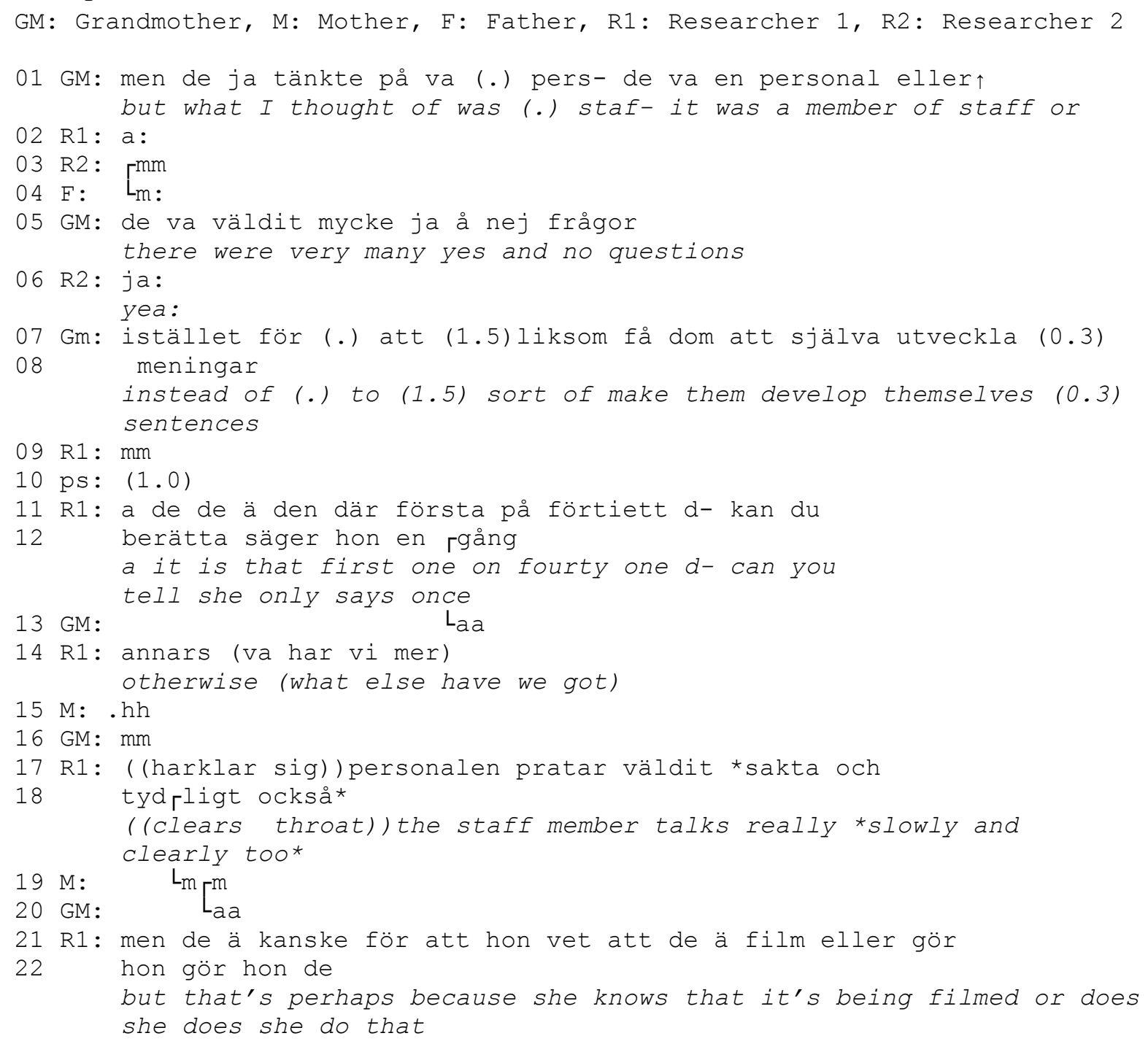




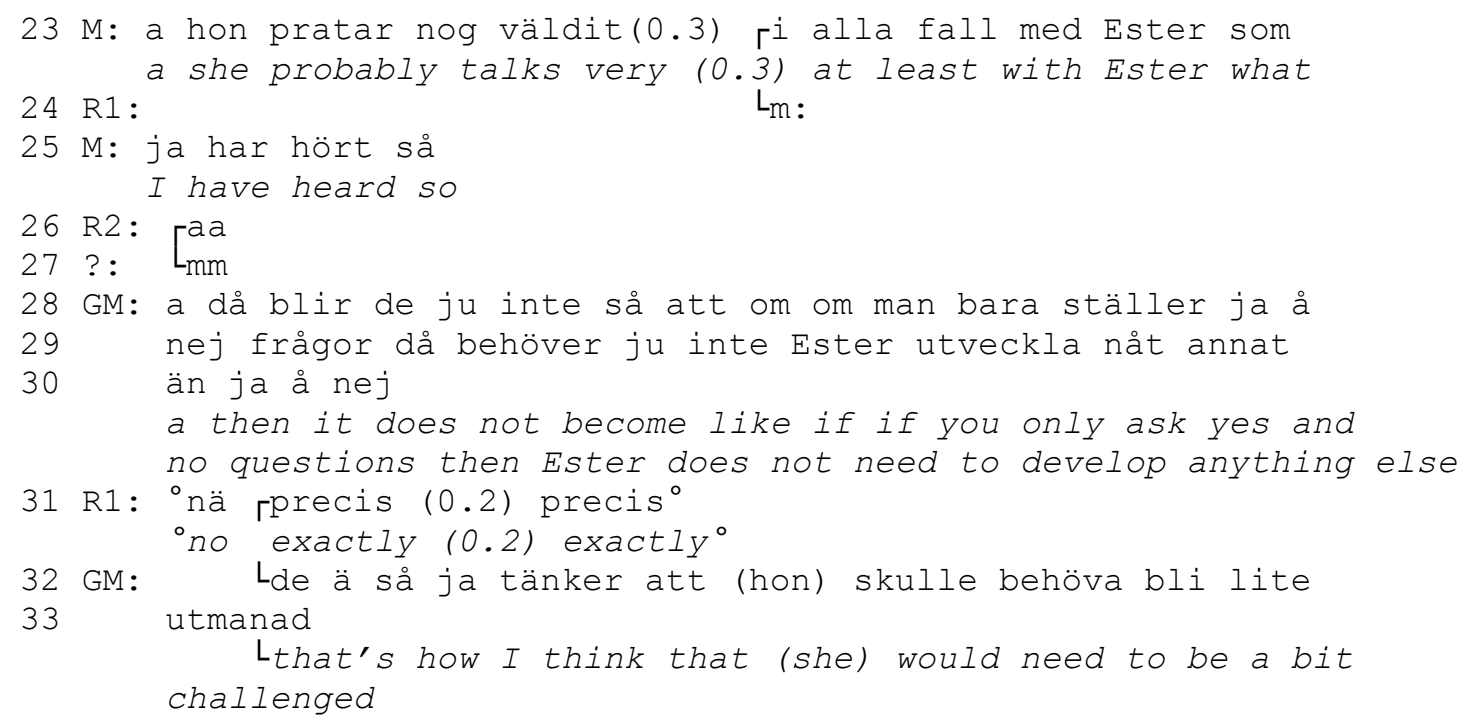

In this excerpt, the grandmother indicates that she thinks the pre-school teacher addresses the children with a lot of yes/no-questions instead of making them use more complex utterances (lines 01, 05, and 07-08). This is followed by a comment by R1 concerning the speech rate of the pre-school teacher, asking if this is her usual style (lines 17 and 21-22). The grandmother then returns to the issue of yes/no-questions, concluding that this kind of contribution does not challenge Ester to develop anything else but yes and no; something that the grandmother thinks would be good for her (lines 28-30, and 32-33). R1 (lines 11-12, and 14) uses the transcription to point to a place in the interaction in which the staff member does something else than just asking yes/no-questions. Participants here collaboratively orient to the transcription of the key episode in order to look at, and discuss the observation made by Ester's grandmother. From this excerpt, implications for intervention are obvious, pointing towards potential issues for advice concerning interactional strategies that could be beneficial for developing Ester's ability to participate more actively in talk. Since Ester has both grammatical and phonological problems, it is important that she is encouraged to use longer utterances in interaction in order to develop her grammatical skills. This is particularly important in everyday settings, because this is harder to practice during therapy sessions. This makes the comment from the grandmother relevant both for parents and for the SLT. 


\section{Assessment of positive performance}

The SLTs sometimes commented on transfer of targeted speech sounds in the child's everyday interaction. Excerpt 3 is taken from an episode of interaction between Hanna, and her friend at the pre-school when they are planning a birthday party. During a retrospection session at the SLT clinic, the SLT observes that Hanna is using one of the speech sounds that have been a target of intervention during spontaneous speech production. The instance is listened to again carefully by the SLT, and the two participating researchers. The sequence is closed by consensus regarding the production of the targeted sound.

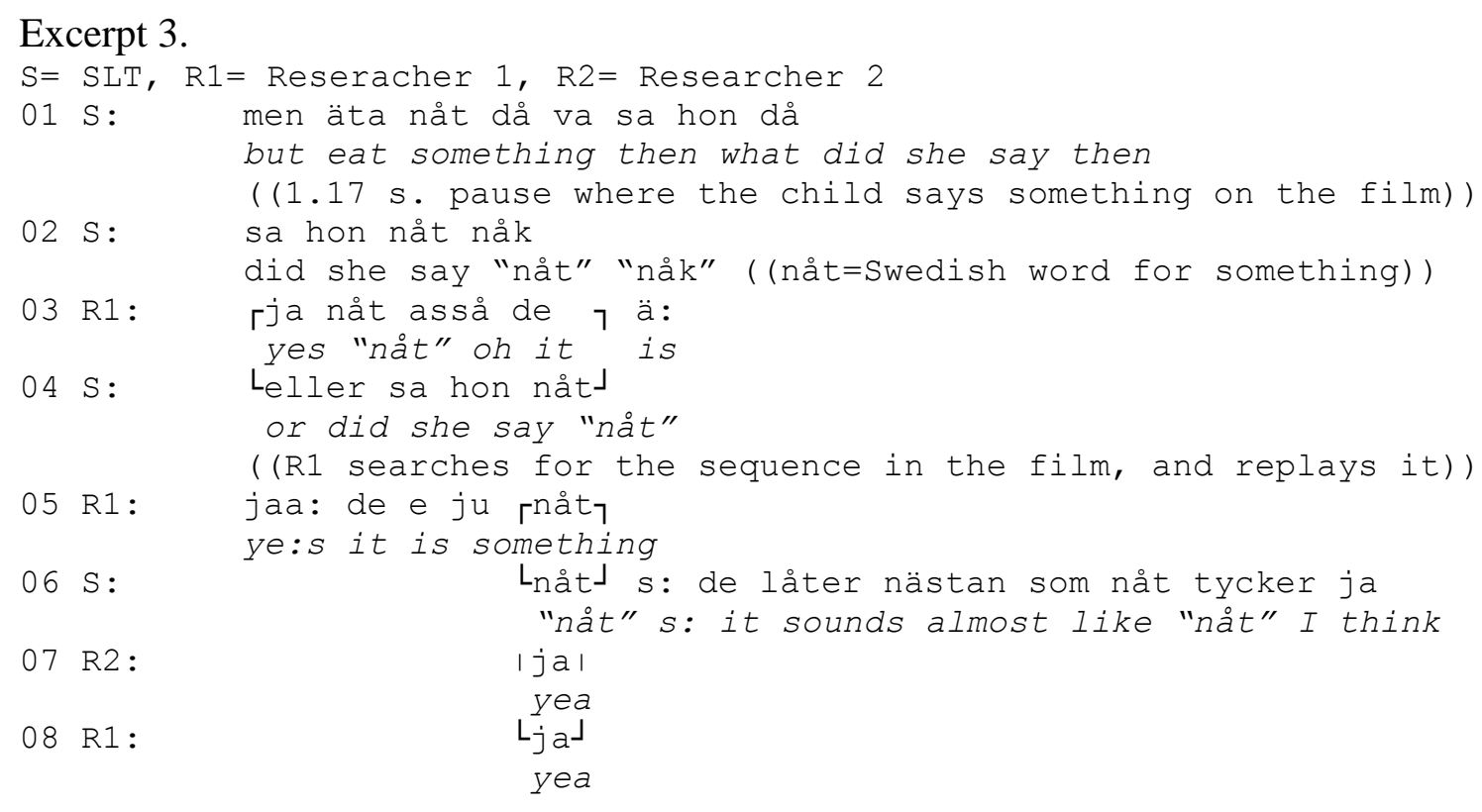

In this excerpt, the SLT observes that Hanna may have used a dental stop, /t/, instead of a velar /k/ (which is one of Hanna's speech errors), in the Swedish word for something, "nåt" (lines 01-02). R1 and the SLT agree in overlap that there is something similar to a dental stop there (lines 03-04), and R1 rewinds the film in order to listen to the sequence one more time. After watching and listening again, R1 confirms that Hanna is indeed pronouncing the word 
"not" with a dental stop /t/ (line 05), and this is confirmed by the SLT (line 06). This observation receives concluding confirmation by R2 and R1 in overlap (lines 07-08). Thus, excerpt 3 illustrates how retrospection may be used to observe generalization effects of phenomena/problems that have been worked on in intervention into everyday settings. In this case, the video clip was taken from a conversation between Hanna and her peer at the preschool, and the SLT identified the word-final use of a dental stop as a confirmation of successful intervention regarding this particular sound.

Excerpt 4 was generated in retrospection at the SLT clinic with Saga's mother, the SLT, and two researchers, R1 and R2. It represents an example of a positive assessment from the mother regarding Saga's interaction with unknown people at the pre-school. The video-clip shows an occasion where Saga approaches one of the researchers when data was collected. This example demonstrates how the viewing of video-recordings from a child's everyday situation may inform parents of progress in their child's interactional skills.

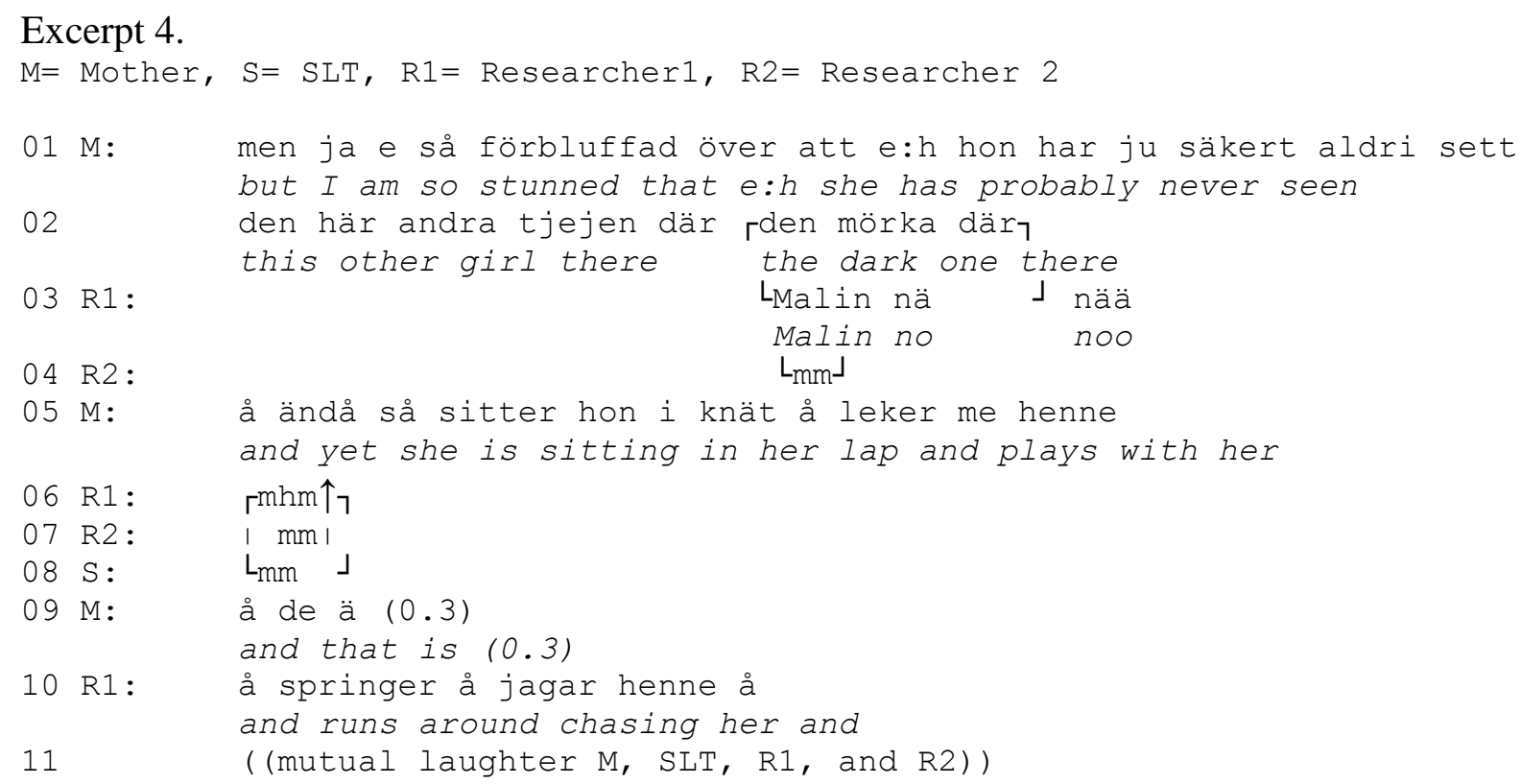


In excerpt 4, Saga's mother expresses her positive astonishment about her daughter's behaviour (lines 01-02), both researchers and the SLT respond with supportive feedback (lines 03-04, and 06-08). Saga's mother starts another comment, but as she makes a brief pause (line 09), R1 collaboratively continues by adding a comment on the openness of Hanna (line 10). The sequence ends with mutual laughter. These kinds of insights gained from watching video-clips of a child in a context outside of the home, or the clinic, are beneficial for parents as well as the SLT, as they add to the overall picture of the child's interactional skills, and of potential consequences (or not) of the LI in the child's everyday life.

\section{Comments relating to intervention}

Excerpt 5 exemplifies how retrospection may generate comments from parents on their perception of the speech and language intervention of their child. The episode occurred in a retrospection session at the SLT clinic together with the parents and grandmother of Ester, in relation to a specific question raised by one of the researchers. The video-clip concerned an intervention session where the SLT and Ester worked with different speech sounds by means of associating the sounds with certain items, e.g. a snake or a rocket.

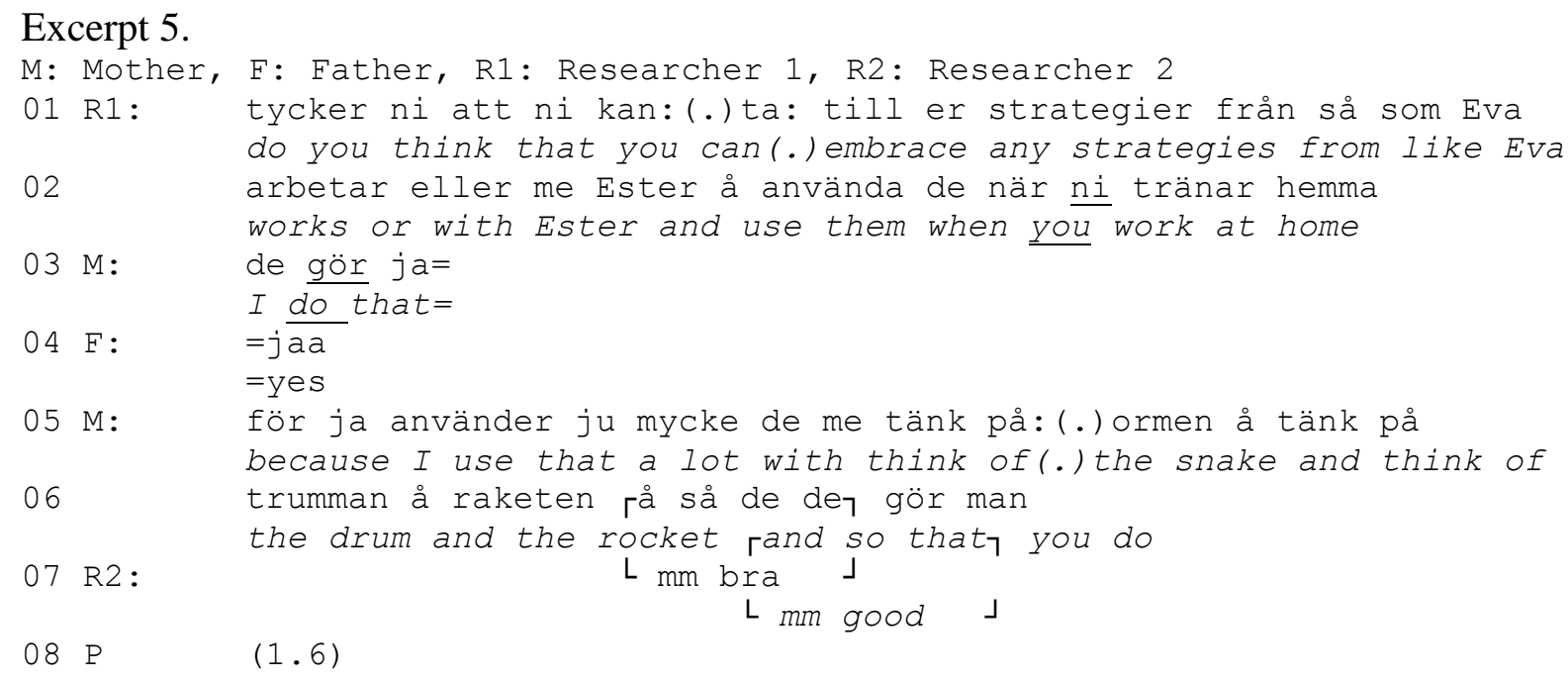


In this excerpt, R1 poses a direct question about whether or not the parents make use of strategies from intervention (lines 01-02), and both parents respond that they do (lines 03-04). Ester's mother also elaborates on this matter (lines 05-06), by giving examples of how she uses intervention strategies at home. This is encouraged by the reinforcing feedback from R2 (line 07). This excerpt illustrates how parents may be encouraged to reflect upon how they may contribute to their child's improvement by bringing aspects of intervention into practices in everyday life. Even though the researcher poses a direct question, it is reasonable to believe that the video-clip just watched, was helpful for the parents in remembering features of the intervention that they have adopted and utilized in every-day situations at home.

Excerpt 6 was generated during retrospection with Emil, his mother, and two researchers. The video-clip shows a part of intervention where voiced stops are in focus. This episode illustrates how a video-clip can be used to receive comments from the participating children regarding intervention.

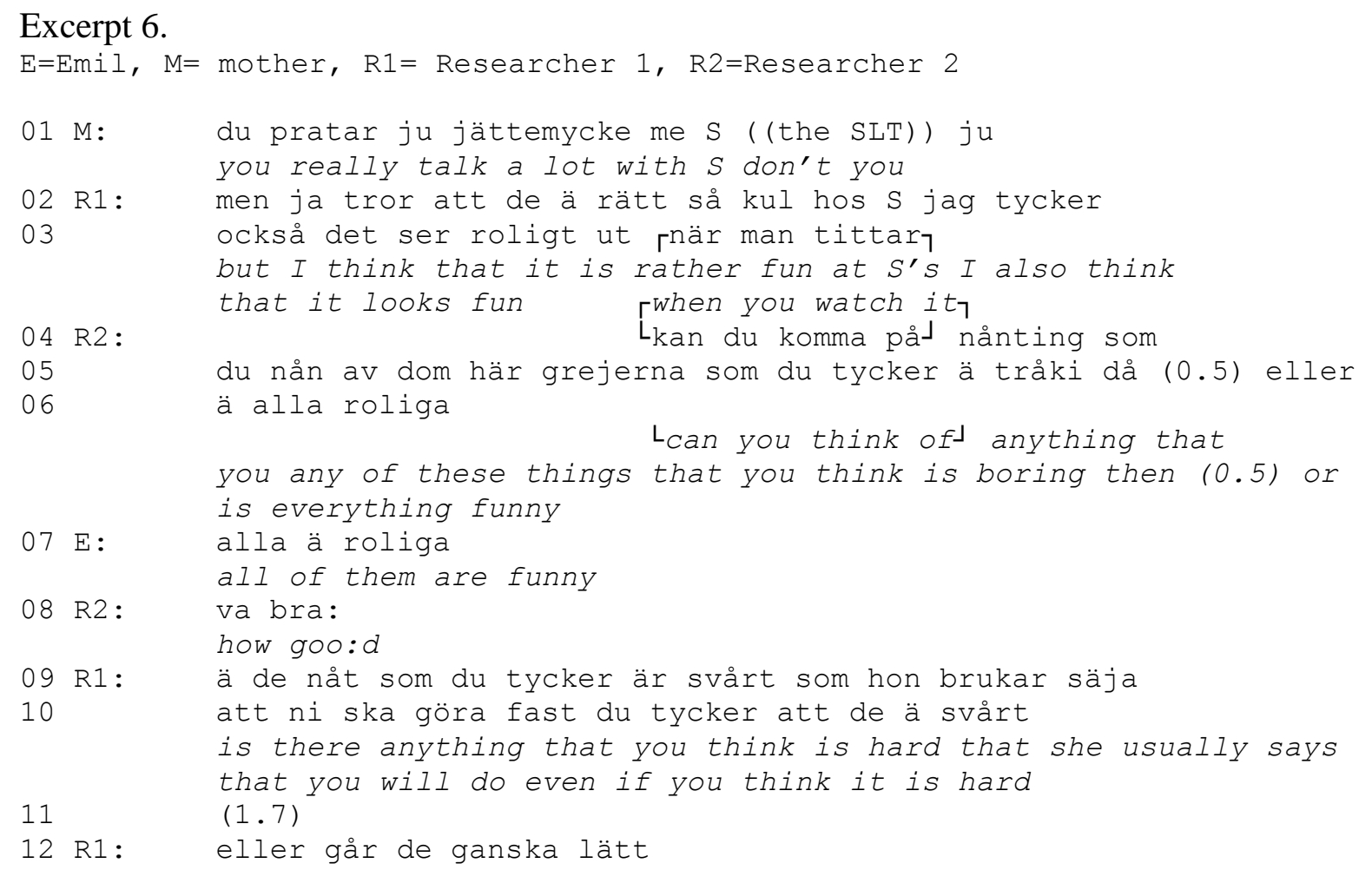




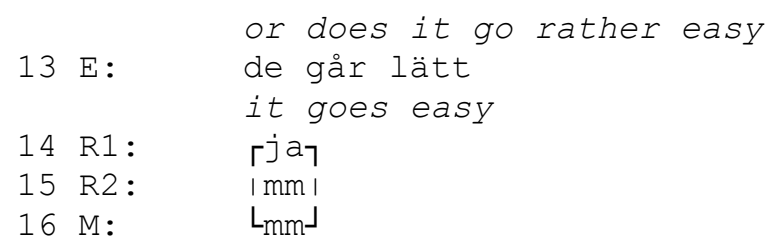

In excerpt 6, Emil's mother gives an account of her child's view of the intervention (line 01), which is followed by a comment from one of the researchers (lines 02-03). The other researcher turns to the child and asks directly about his viewpoint (lines 04-06), and he responds that everything is funny (line 07). R1 asks Emil if there is anything that he finds hard (lines 09-12), but he says that everything is easy (line 13). This answer is acknowledged by both researchers and the child's mother (lines 14-16). This excerpt demonstrates how a child is actively, verbally contributing during the retrospection. However, explicit questions that offer two alternatives (boring vs. fun, and hard vs. easy) from the adults are used in order to elicit the viewpoints of the child. Cahill (2010) has also commented on the need for explicitly giving the word to children in clinical consultations. In that respect, the response of the child is directive to some degree, and less spontaneous in comparison to comments from adults, for whom it is easier to relate the contents of the video, to aspects of the child's language abilities, and to intervention.

For this child, it was clear from the recordings of intervention sessions that improved pronunciation was targeted in intervention, and the discussion in the retrospection illustrates that both the mother and the participating child are satisfied with how this is targeted in terms of the child's satisfaction with the exercises at the SLT's clinic.

\section{Summary}

This selection of comments generated from the retrospection sessions show that participants and researchers acknowledge and highlight interactional strategies and phenomena that in 
various ways reflect issues related to the child's communicative impairment, interactional behaviours from everyday settings, and relevant aspects of intervention. In several of the excerpts, the researchers initiate reflections on adult-child interaction from the selected videoclips, e.g. lines 01-03 in excerpt 1 , line 11 in except 2 and line 01 in excerpt 5. These initiations are made both by specific comments and by explicit questions about reflections on communicative behaviour. These initiations are responded to with minimal or elaborated responses from participating parents and SLTs. The parents, or other relatives, and the participating SLTs initiated discussion points to a somewhat lesser extent. The results also reveal that the use of retrospection may serve an awareness-raising purpose for all participants, not least for the SLTs.

\section{Discussion}

The results from the retrospections based on CA-methodology demonstrate how participants' perspectives on interaction may be brought to the fore. Examples of reflections by children, their parents, SLTs, and researchers concerned various issues relating to interactional phenomena that are relevant for intervention. These phenomena include strategies beneficial for communication, for example how a mother provided her child with time to finish the completion of an utterance (Excerpt 1). They also include situations where relatives displayed their awareness of interactional patterns relevant for the child with LI (Excerpt 2). In addition, SLTs acknowledged the generalisation of speech sounds that were the target of intervention, into everyday use (Excerpt 3), and parents observed interactional behaviour in their children outside of the home, that they did not know that they were capable of (Excerpt 4). Children's and parents' opinions of the intervention, as well as how parents perceived they could understand and use strategies from the intervention, were also brought to the surface (Excerpts 5, and 6). 
The status of participants' retrospective comments as re-constructions of a past event when combining CA-methodology with talk-extrinsic data has been discussed by Antaki (2012), Ford (2012), and Pomerantz (2012) and this is aligned with in the present study. Here, in contrast to the study by Waring et al. (2012), comments generated in the retrospections have been used in their own right to focus on interactional behaviours and practices that are relevant for language intervention for the children with LI. They have not been used to confirm or disconfirm any observations made through the use of CA. CA formed the basis on which the initial analyses of data-sets one and two were performed, and it governed the selection of key-episodes and categories. Participants' comments, in relation to the keyepisodes, were treated for what they were; retrospective statements about issues that the participants wanted to highlight there and then. Together, observations from the initial analyses and retrospective sessions were then related to the aim of investigating interactional features relevant for intervention and everyday interactional needs of the children with LI.

The results of this study support previous research that shows how interactional approaches to speech and language intervention are beneficial in providing parents with advice on various communication strategies, and enhancing their ability to evaluate changes in interactional patterns (e.g. Gardner, 2006; Ovreeide and Hafstad, 1996; Pepper and Weitzman, 2004). Results also demonstrate how this method has potential to develop an intervention programme for children with LI, similar to that which is being developed for adults with aphasia (Beeke et al., 2011). Previous studies of interaction have primarily focussed on changes in the interactional behaviour of parents, whereas the present study includes the viewpoints of children. The results demonstrate that children may also be active during retrospection sessions, e.g. commenting upon intervention activities. This may require some work from the 
adults present to actively engage the child with explicit requests for their opinion. Whilst it may be encouraging for the child to be asked explicit questions, this might also be demanding for some children. Another way of actively engaging the child would be to choose video-clips from play sequences considered to be funny and engaging for the child. However, in order to elicit specific comments on the intervention per se, it was sometimes also necessary to ask explicit questions to parents. Children did provide spontaneous comments while watching the videos, although these comments have not been reported in the results section. Such comments often concerned the actions occurring in the films, relating to what the child or his/her friends were doing, or were requests to watch the same episode again.

An advantage of conducting retrospections was to give an opportunity for parents and SLTs to view children in different interactional contexts. This allows the possibility to relate features from everyday interaction to goals of intervention, and vice versa, providing more knowledge concerning the relationship between the child's scores from formal tests, the goals of intervention set up based on these tests, and the child's actual performance outside of intervention. Clearly, the use of retrospection may work as an additional tool for making intervention more person-centred, and better suited to the clients' everyday communication needs (Johnston, 2006). As demonstrated in this study, it also provides the SLT with the opportunity to observe how specific goals of intervention, e.g. targeted sounds, are adequately used or not by the child, outside of the clinical setting. Viewing video-recordings of a client in interaction with other children and adults (e.g. pre-school teachers) provides valuable information for the SLT to use in adapting the intervention to the needs of an individual child. There is also a need for development of assessment tools that are based on speech and language problems as they occur in everyday interaction, that sometimes, but not always, concur with the problems identified by established, formal tests. Such assessment methods, 
may complement formal test, and thereby influence speech and language intervention, adding to its ecological validity.

An important function of retrospections is to raise the awareness of all participants as regards various interactional features relevant for intervention, as well as for everyday talk. Wellfunctioning communication strategies can be acknowledged and encouraged, and problematic interactional behaviours can be targeted and discussed. During retrospection sessions it became apparent that participants felt the need to discuss language and interactional problems outside of speech and language intervention. The involvement of clients and their family is becoming increasingly important, perhaps especially for children. Cahill (2010) has demonstrated that in primary-care consultations, although doctors did engage with the children during consultations, $95 \%$ of the talk occurred between the parents and the doctors, with the children as bystanders. According to Swedish legislation, and in the code of ethics of health-care workers, the opinions of patients should be taken into consideration when making decisions, e.g. of intervention. The present study reveals that a systematic use of retrospection based on CA-analysis, may be one way to elicit comments and viewpoints from children with LI, and to receive general insights on everyday interactional practices that may be beneficial for forming intervention that is tailor-made for a particular child, in addition to results of formal tests.

There are some potential pitfalls in using retrospections. For example, before a retrospection session, researchers have to make a selection of episodes of interaction to be viewed, since it is not feasible to watch everything that has been recording. This naturally influences what phenomena may be discussed during retrospections, thus limiting the number of patterns and behaviours that are commented on by participants. When using retrospection in clinical 
practice, the selection of video clips benefits from being guided by clinical judgement following clients' needs and requests. The focus should be on how comments can be useful in developing goals of intervention that are as ecologically valid and relevant as possible for a specific child. Each retrospective comment should therefore be assessed in its own right in relation to the goals of intervention as based on formal tests, and in relation to observations made in video-recordings from various everyday settings. Those who are involved in adapting intervention in accordance with results of formal tests, and patterns detected in retrospective sessions, need to be critical and able to assess retrospective comments in a sound way, in order to optimize their usefulness in clinical practice.

Another limitation of the present study was that the researchers were very attentive not to expose participants to data that were delicate, or face-threatening, since viewing one's own communicative inabilities and weaknesses may cause a painful self-disclosure. This may be a difficult balance to reach if using retrospection in clinical practice. However, children with LI are not always very aware of their problems, and therefore may be less prone to negative feelings around their behaviour, although their parents may be more concerned. This issue deserves further attention in the development of using retrospections for intervention purposes.

Despite the potential difficulties highlighted, the practice of retrospection provides information that can contribute to the further development of person-centred, ecologically valid intervention for children with LI. However, the retrospection ought to derive from a CAanalysis of data from intervention and everyday settings where specific functions and consequences of contributions is focused, and include retrospective comments by children with LI, parents and relatives, and SLTs. This procedure of retrospection based on CA- 
methodology might seem time consuming. However, as one becomes familiar with, and trained in viewing and assessing video-recorded interactions from a CA-perspective, it becomes easier and faster to identify the aspects of interaction are of relevance for a specific patient and his/her intervention. However, the use of retrospection as outlined here is likely to be time well spent in order to make language therapy as efficient as possible.

\section{Conclusion}

This study aims to explore if retrospection based on CA-methodology may be a potentially useful method to be employed in language intervention for children with LI. Using CA, highly detailed analyses can be performed on video- and audio-recorded data. Recordings of a range of different settings, such as intervention, and various everyday activities, allow SLTs, parents, and relatives to get an overview of the communicative abilities of a child with LI that might otherwise be hard to obtain. Retrospections raise participants' awareness of their own interactional behaviours, and provide the opportunity to discuss strategies relevant for intervention as well as everyday interaction (cf. Beeke et al. 2011). The results presented here support the future use of retrospection based on CA-methodology for speech and language intervention for children with LI, and as a method in clinical training of SLTs. This might include the use of data from everyday settings in addition to regular test results, and regular intervention practises. Of particular relevance would be to develop a programme for children with LI, since such approaches at present, are sparse for this clinical group.

\section{Acknowledgements}

We would like to thank all participating families and SLTs. We are also grateful to Professor Paul Fletcher, who made valuable comments on earlier versions of this paper. 


\section{Funding}

The present study is part of the project Interaction and intervention. People with communicative disabilities in clinical and everyday interaction, funded by The Swedish Research Council (VR) grant no: 2010-1440. 


\section{Appendix One}

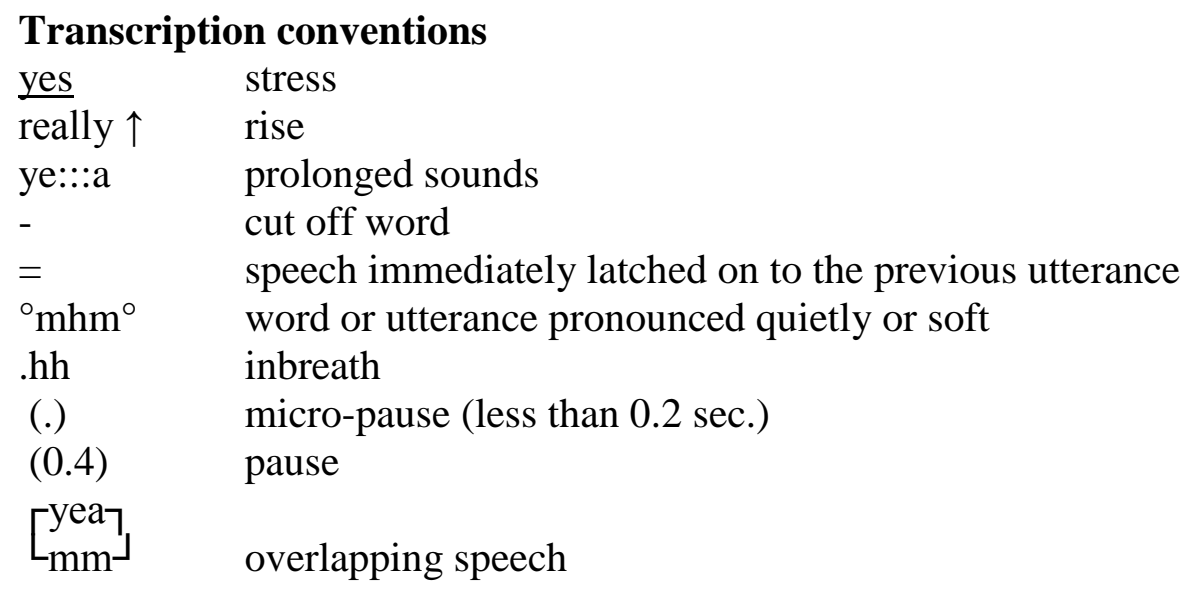




\section{References}

Aarts M (2000) Marte Meo--Basic Manual. HarderWijk: Aarts Productions.

Antaki C (2012) What actions mean, to whom, and when. Discourse Studies 14 493-498.

Axberg U, Hansson K, Broberg A G and Wirtberg I (2006) The development of a systemic school-based intervention: Marte Meo and coordination meetings. Family Process 45: 375-389. doi: 10.1111/j.1545-5300.2006.00177.x

Beeke S, Maxim J, Best W and Cooper F (2011) Redesigning therapy for agrammatism: initial findings from the ongoing evaluation of a conversation-based intervention study. Journal of Neurolinguistics 24, 222-236.

Bishop, D. (1997) Uncommon Understanding. Development and Disorders of Language Comprehension in Children. Hove, UK: Psychology Press.

Cahill P (2010) Children's participation in their primary care consultations. In: H. Gardner and M. Forrester (Eds), Analysing Interactions in Childhood. Insights from Conversation Analysis. Chichester: Wiley-Blackwell. Pp. 128-145.

Camarata S M and Nelson K E (2006) Conversational recast intervention with preschool and older children. In R. J. McCauley and M. E. Fey (Eds) Treatment of Language Disorders in Children. Baltimore: Paul H. Brookes Publishing Co. Pp 237-264.

Coulter L and Gallagher C (2001) Evaluation of the Hanen Early Childhood Educators Programme. International Journal of Language and Communication Disorders 36 (s1), 264-269.

Erickson F and Schultz J (1982) The Counselor as Gatekeeper; Social Interaction in Interviews. New York: Academic Press.

Fey M (1986) Language Intervention with Young Children. Boston, MA: College-Hill.

Ford C (2012) Clarity in applied and interdisciplinary conversation analysis. Discourse Studies 14, 4, 597-613.

Gardner H (2006) Training others in the art of therapy for speech sound disorders: an interactional approach. Child Language Teaching and Therapy 22, 1, 27-46.

Gardner H and Forrester M (2010) Analysing Interactions in Childhood. Insights from Conversation Analysis. Chichester: Wiley-Blackwell.

Hancock T B and Kaiser A P (2006) Enhanced milieu teaching. In R. J. McCauley and M. E. Fey (Eds) Treatment of Language Disorders in Children. Baltimore: Paul H. Brookes Publishing Co. Pp 203-233.

Hutchby I and Wooffitt R (2008) Conversation analysis. Cambridge: Polity.

Johnston J (2006) Thinking about Child Language. Research to Practice. Eau Claire, Wisconsin: Thinking Publications.

Lock S, Wilkinson R, Bryan K, Maxim J, Edmundson A and Moir D (2001) Supporting Partners of People with Apahsia in Relationships and Conversation (SPPARC). International Journal of Language and Communication Disorders 36, Suppl 25-30.

Merrils D (2009) Staying on the same wavelength: Talking about talking in paediatric speech and language therapy sessions. Clinical Linguistics and Phonetics 23(1): 70-91.

Merrison S and Merrison A J (2005) Repair in Speech and Language Therapy Interaction: Investigating Pragmatic Language Impairment in Children, Child Language Teaching and Therapy, Volume 21 (2), 191-211.

Mondada L (2006) Video recordings as the reflective preservation and configuration of phenomenal features for analysis. In H. Knoblauch, J. Raab, H.G. Soeffner, \& B. Schnettler (Eds), Video Analysis. Bern: Lang. Pp 51-68.

Norén N, Samuelsson C and Plejert C (2013) Aided Communication in Everyday Interaction. Guilford: J \& R Press Ltd. 
Ochs E, Schegloff E and Thompson S (1996) (Eds) Interaction and Grammar. Cambridge: Cambridge University Press.

Ovreeide H and Hafstad R (1996) The Marte Meo Method and Developmental Supportive Dialogues. Bergen, Norway: Aarts Productions.

Pennington L, Thomson K, James P, Martin L and Mcnally R (2009) Effects of It Takes Two to Talk-The Hanen Program for parents of preschool children with cerebral palsy:

Findings from an exploratory study. Journal of Speech, Language, and Hearing Research $52,1121-1138$.

Pepper J and Weitzman E (2004) It Takes Two to Talk: A Practical Guide for Parents of

Children with Language Delays (3rd ed.). Toronto, Ontario, Canada: Hanen Centre.

Pomerantz A (2005) Using Participants' video stimulated comments to complement analyses of ineractional practices. In: $\mathrm{H}$ te Molder and J Potter (eds) Talk and Cognition: Discourse, Mind and Social Interaction. Cambridge: Cambridge University Press. Pp. 93-113.

Pomerantz A (2012) Do participants' reports enhance conversation analytic claims? Explanations of one sort or another. Discourse Studies 14, 4, 499-505.

Radford J and Mahon M (2010) Multi-modal participation in storybook sharing. In: H. Gardner and M. Forrester (Eds), Analysing Interactions in Childhood. Insights from Conversation Analysis. Chichester: Wiley-Blackwell. Pp 209-226.

Schegloff E A, Jefferson G and Sacks H (1977). The preference for self-correction in the organization of repair in conversation. Language 53 (1-2): 361-82.

Schegloff E A (2007) Sequence Organization in Interaction. A Primer in Conversation Analysis. Cambridge: Cambridge University Press.

Sillars A, Roberts L J, Leonard K E and Dun T (2000) Cognition during marital conflict: The relationship of thought and talk. Journal of Social and Personal Relationships, 17, 479502.

Stribling P and Rae J (2010) Interactional analysis of scaffolding in a mathematical task in ASD. In: H. Gardner and M. Forrester (Eds), Analysing Interactions in Childhood. Insights from Conversation Analysis. Chichester: Wiley-Blackwell. Pp 185-208.

Tykkyläinen T (2010). Child-initiated repair in task interactions. In: H Gardner and M Forrester (Eds), Analysing Interactions in Childhood. Insights from Conversation Analysis. Chichester: Wiley-Blackwell. Pp 227-248.

Waring H Z, Creider S, Tarpey T and Black R (2012) A search for specificity in understanding CA and context. Discourse Studies 14, 4, 477-492.

Wilkinson R (2013) Gestural depiction in acquired language disorders: On the form and use of iconic gestures in aphasic talk-in-interaction. Augmentative and Alternative Communication 29 (1): 68-82. 